University of Nebraska - Lincoln

DigitalCommons@University of Nebraska - Lincoln

$9-1-2007$

\title{
Thermal stability of nanostructurally stabilized zirconium oxide
}

\author{
Fereydoon Namavar \\ University of Nebraska Medical Center, Omaha, NE \\ Gonghua Wang \\ University of Nebraska-Lincoln \\ Chin Li Cheung \\ University of Nebraska-Lincoln, ccheung2@unl.edu \\ Renat F. Sabirianov \\ University of Nebraska at Omaha, rsabirianov@mail.unomaha.edu \\ Xiao Cheng Zeng \\ University of Nebraska-Lincoln, xzeng1@unl.edu \\ See next page for additional authors
}

Follow this and additional works at: https://digitalcommons.unl.edu/chemzeng

Part of the Chemistry Commons

Namavar, Fereydoon; Wang, Gonghua; Cheung, Chin Li; Sabirianov, Renat F.; Zeng, Xiao Cheng; Mei, Wai Ning; Bai, Jaeil; Brewer, Joseph R.; Haider, Hani; and Garvin, Kevin L., "Thermal stability of nanostructurally stabilized zirconium oxide" (2007). Xiao Cheng Zeng Publications. 77.

https://digitalcommons.unl.edu/chemzeng/77

This Article is brought to you for free and open access by the Published Research - Department of Chemistry at DigitalCommons@University of Nebraska - Lincoln. It has been accepted for inclusion in Xiao Cheng Zeng Publications by an authorized administrator of DigitalCommons@University of Nebraska - Lincoln. 


\section{Authors}

Fereydoon Namavar, Gonghua Wang, Chin Li Cheung, Renat F. Sabirianov, Xiao Cheng Zeng, Wai Ning Mei, Jaeil Bai, Joseph R. Brewer, Hani Haider, and Kevin L. Garvin 


\title{
Thermal stability of nanostructurally stabilized zirconium oxide
}

\author{
Fereydoon Namavar ${ }^{1}$, Gonghua Wang ${ }^{2}$, Chin Li Cheung ${ }^{2,4}$, Renat \\ F. Sabirianov ${ }^{3}$, Xiao Cheng Zeng ${ }^{2}$, Wai Ning $\mathrm{Mei}^{3}$, Jaeil Bai², \\ Joseph R. Brewer ${ }^{2}$, Hani Haider ${ }^{1}$, and Kevin L. Garvin ${ }^{1}$ \\ ${ }^{1}$ Department of Orthopedic Surgery and Rehabilitation, University of Nebraska Medical Center, \\ Omaha, NE 68198, USA \\ ${ }^{2}$ Department of Chemistry and Nebraska Centre for Materials and Nanoscience, University of \\ Nebraska-Lincoln, Lincoln, NE 68588, USA \\ ${ }^{3}$ Department of Physics, University of Nebraska-Omaha, Omaha, NE 68182, USA \\ ${ }^{4}$ Corresponding author: email: ccheung2@unl.edu
}

\begin{abstract}
Nanostructurally stabilized zirconium oxide (NSZ) hard transparent films were produced without chemical stabilizers by the ion beam assisted deposition technique (IBAD). A transmission electron microscopy study of the samples produced below $150{ }^{\circ} \mathrm{C}$ revealed that these films are composed of zirconium oxide $\left(\mathrm{ZrO}_{2}\right)$ nanocrystallites of diameters $7.5 \pm 2.3 \mathrm{~nm}$. X-ray and selected-area electron diffraction studies suggested that the as-deposited films are consistent with cubic phase $\mathrm{ZrO}_{2}$. Rutherford backscattering spectroscopy (RBS) indicated the formation of stoichiometric $\mathrm{ZrO}_{2}$. The phase identity of these optically transparent NSZ films was in agreement with cubic $\mathrm{ZrO}_{2}$, as indicated by the matching elastic modulus values from the calculated results for pure cubic zirconium oxide and results of nanoindentation measurements. Upon annealing in air for $1 \mathrm{~h}$, these NSZ films were found to retain most of their room temperature deposited cubic phase $\mathrm{x}$-ray diffraction signature up to $850{ }^{\circ} \mathrm{C}$. Size effect and vacancy stabilization mechanisms and the IBAD technique are discussed to explain the present results.
\end{abstract}

\section{Introduction}

Zirconium oxide $\left(\mathrm{ZrO}_{2}\right)$ films have attracted immense attention as an important ceramic material because of their superior chemical, mechanical, and optical properties. They have high chemical stability, hardness among those of steel and other alloys [1], dielectric constant among the highest for metallic oxides [2], low absorption of light and high index of refraction [3]. These films have been exploited for a broad range of applications from thermal-barrier coatings [4], wear resistance coatings [5], protective coating for optical mirrors and filters [3], high temperature fuel cells [6], oxygen detectors [6] to catalyst supports [7]. The objective of our present work is the development of biocompatible transparent coating for biomedical and tissue engineering applications $[8,9]$.
Zirconium oxide exhibits different structural polymorphs [10]. The most common ones are monoclinic, tetragonal and cubic phases. The tetragonal phase $\left(P 4_{2} / n m c\right)$ has been the preferred material for wear and mechanical applications because it has high fracture resistance. The cubic phase $(\mathrm{Fm} 3 \mathrm{~m})$ is a diamond simulant because of its high refractive index. Nevertheless, pure $\mathrm{ZrO}_{2}$ is not stable in the cubic phase or tetragonal phase at room temperature. Addition of trivalent dopants and oversized/undersized tetravalent dopants into $\mathrm{ZrO}_{2}$ is known to stabilize these metastable phases by creating oxygen vacancies to energetically favor such structures. Cubic phase $\mathrm{ZrO}_{2}$ is mostly produced by the addition of up to $20 \%$ trivalent stabilizer oxides such as yttria or ceria [11]. However, the mechanical properties of such $\mathrm{ZrO}_{2}$ material deteriorate with large concentrations of stabilizing oxides [12]. While calcia- 
stabilized single-phase cubic $\mathrm{ZrO}_{2}$ films have been reported by sputtering at high temperatures above $400{ }^{\circ} \mathrm{C}$ [13], fabrication of pure cubic $\mathrm{ZrO}_{2}$ transparent hard films have not yet been demonstrated at room temperature.

Another mechanism to stabilize cubic $\mathrm{ZrO}_{2}$ is to exploit the size effect to generate nanocrystalline cubic $\mathrm{ZrO}_{2}$ with an average grain size of $15 \mathrm{~nm}$, mostly in powder form, by sol-gel, ball milling, spray pyrolysis and other techniques [14-17]. Tetragonal phase of $\mathrm{ZrO}_{2}$ powder has also been reported in the nanocrystalline phase with larger particle sizes [18-20]. Thermal stability studies of metastable tetragonal phase $\mathrm{ZrO}_{2}$ synthesized via the sol-gel method report that these materials revert to monoclinic phase upon heating above $300{ }^{\circ} \mathrm{C}$ [21] or even above $400{ }^{\circ} \mathrm{C}[22]$. Further study suggests that the thermal stability of these films depends strongly on the film thickness, with thicker and denser films being more thermally stable [23]. Nonetheless, it is problematic and impractical to produce adherent hard protective coating utilizing ceramic powders for load bearing applications.

Ion beam assisted deposition (IBAD) combines evaporation with concurrent ion beam bombardment in an ultrahigh vacuum environment [24] at a vacuum base pressure of $10^{-}$ ${ }^{8}$ Torr. By examining different deposition conditions, such as ion to atom (arrival) ratios, ion energies and substrate temperatures for the IBAD process, the size of the nanocrystallites and the possibility to create vacancies in the crystallites can be controlled to produce metastable films without chemical stabilizers. Optimization of the ion bombardment conditions can also modulate the morphology, density, stress level, crystallinity, and chemical composition of the as-produced films with excellent adhesion to the substrates. IBAD has been previously applied and studied for $\mathrm{ZrO}_{2}$ film deposition [25, 26] using argon ions in the kiloelectronvolt energy range which resulted apparently in non-stoichiometric opaque zirconia. We have also observed similar results in our laboratory when only $\mathrm{Ar}$ ions, especially with high energy ions and high current density, were used to fabricate $\mathrm{ZrO}_{2}$ films. Furthermore, bombardment of material with kiloelectronvolt energy range ions often resulted in accumulation of projectiles such as argon $[25,26]$ and even formation of nitrogen bubbles [27] or solid krypton [28].

In this paper, we report the growth and thermal stability of nanostructurally stabilized (NSZ) $\mathrm{ZrO}_{2}$ transparent films free of chemical stabilizers by IBAD with low energy ion beams (0-600 eV) using both RF and DC plasma ion sources. The measured nanohardness values of these films are similar to that of the calculated values for cubic phase $\mathrm{ZrO}_{2}$. Rutherford backscattering spectroscopy (RBS) study and detailed x-ray and electron diffraction analysis of our NSZ films indicate the formation of stoichiometric cubic phase $\mathrm{ZrO}_{2}$.

\section{Experimental details}

We designed and fabricated chemical stabilizer-free $\mathrm{ZrO}_{2}$ nanocrystalline films by the IBAD technique. Our IBAD system is comprised of a Veeco $12 \mathrm{~cm}$ RF ion gun that supplies ions at energies up to $1500 \mathrm{eV}$ with a total current density of
$500 \mathrm{~mA}$ which provides a broad uniform ion beam of oxygen, nitrogen and argon, a DC ion gun with an ion density of $3 \mathrm{~A}$ at energies up to $150 \mathrm{eV}$, a thermal evaporation source and a programmable sweep multi-pocket for electron beam evaporation source. All depositions were performed in an ultra-clean vacuum system with a base pressure at $10^{-8}$ Torr with a working pressure of $10^{-4}-10^{-5}$ Torr. Nanocrystalline films of $\mathrm{ZrO}_{2}$ were prepared by electron beam evaporation of $99.7 \%$ pure monoclinic $\mathrm{ZrO}_{2}$ (Alfa Aesar, lot \# C01P41) at a rate of 0.5-2 $\AA \mathrm{s}$ ${ }^{1}$ onto silicon wafers, glass, quartz, grafoil, stainless steel, cobalt, chromium, and ultra-high molecular weight polyethylene (UHMPE) substrates. The ion species (mainly oxygen with a mixture of argon and nitrogen) were used to control the chemical and physical properties of the films. The presence of the small percentage of noble gases such as argon helps operation, stability and performance of our ion guns for obtaining the oxygen beam. Furthermore, backfill of ultra-pure oxygen was utilized to ensure formation of stoichiometric $\mathrm{ZrO}_{2}$. Ion energy $(0-600 \mathrm{eV})$ and ion current density $\left(0-500 \mu \mathrm{A} \mathrm{cm}^{-2}\right)$ were optimized to produce $\mathrm{ZrO}_{2}$ films with specific nanostructures. For mechanical testing of these films on metallic substrates, we created a gradual transition between the substrates and the deposited films with less built-in stress and thus a much more durable adhesion to the substrate than other techniques. All substrates were cleaned by an in situ argon ion beam with energy $300 \mathrm{eV}$ for $15 \mathrm{~min}$ before deposition. Over 50 deposits under different deposition conditions were carried out to produce transparent stoichiometric $\mathrm{ZrO}_{2}$ films with high hardness. $\mathrm{ZrO}_{2}$ films without ion bombardment were also produced as controls. A control tetragonal $\mathrm{ZrO}_{2}$ sample was obtained by breaking off a very small piece from a medical device made of medical-grade chemically stabilized tetragonal $\mathrm{ZrO}_{2}$.

Rutherford backscattering spectroscopy (RBS) with a 2.275 $\mathrm{MeV} \mathrm{He}{ }^{2+}$ beam was applied to analyze the chemical composition of $\mathrm{ZrO}_{2}$ films deposited onto silicon, and occasionally grafoil, substrates. The uncertainties of the RBS measurements indicated by our commercial RBS analytical service, Charles Evans Associates, are about 1 at. \% for zirconium concentration and about 4 at.\% for oxygen concentration. The detection limit for argon is about 0.1 at.\%. The surface morphology and crystal structure of the $\mathrm{ZrO}_{2}$ films were characterized by atomic force microscopy (AFM, multi-mode Nanoscope IIIa), transmission electron microscopy (TEM, JEOL 2010 operated at $200 \mathrm{kV}$ ) and $\mathrm{x}$-ray diffractometry (XRD, Bruker AXS D8 Discover with GADDS area detector and Rigaku D/Max-B Xray diffractometer with a conventional copper target $\mathrm{x}$-ray tube set to $40 \mathrm{kV}$ and $30 \mathrm{~mA}$; the weighted average wavelength of the $\mathrm{Cu} \mathrm{K \alpha}$ avg. $=1.5417 \AA$ ). TEM cross-section samples were prepared by the dimpling process and argon ion milling from the back surface. XRD data peak fitting was performed using TOPAS (Bruker AXS, 2004), a whole powder pattern fitting program, with the fundamental parameters' approach. The hardness and bulk moduli of the films were measured by an ultra-low depth sensing nanoindenter [29, 30]. A thermal stability study of $\mathrm{ZrO}_{2}$ films was performed by annealing these samples in a tube furnace open to air for $1 \mathrm{~h}$ and $10 \mathrm{~h}$ at temperatures of $300,500,600,700,800,850,900$, and $1000{ }^{\circ} \mathrm{C}$. 


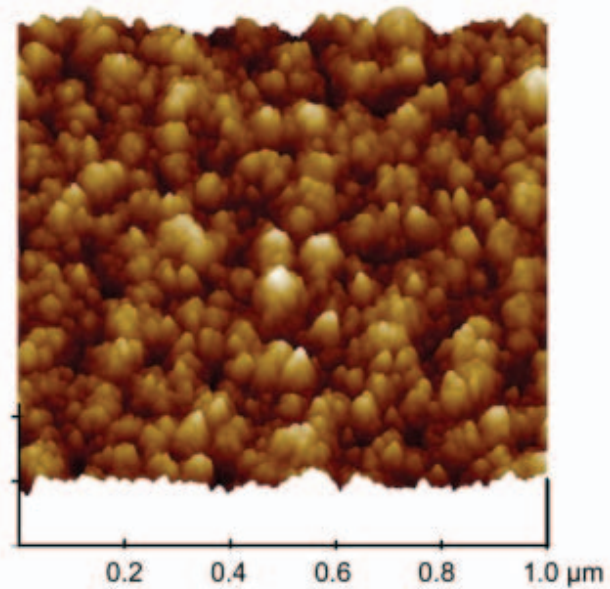

Figure 1. AFM height image of the nanostructurally stabilized $\mathrm{ZrO}_{2}$ film. The $z$ scale is $100 \mathrm{~nm} /$ div. The measured mean roughness $\left(R_{\mathrm{a}}\right)$ of $1 \mu \mathrm{m}^{2}$ is $9 \mathrm{~nm}$.

\section{Results and discussion}

A typical AFM image of as-produced IBAD nanocrystalline $\mathrm{ZrO}_{2}$ films reveals a nanogranular surface morphology with roughness of about $9 \mathrm{~nm}$ (figure 1). Bright-field TEM image (figure 2(b)) and dark-field TEM image (data not shown) of a typical $\mathrm{ZrO}_{2}$ film produced by a $500 \mathrm{eV}$ ion beam confirmed the presence of crystallites with average diameters of $7.5 \pm 2.3 \mathrm{~nm}$ (diameter range: $4-15 \mathrm{~nm}$ ). Selected-area electron diffraction patterns of the sample also imply the possible formation of a randomly oriented cubic structure with proper indexes (figure 2(a)).

The XRD spectra of the NSZ samples were compared to XRD spectra for a chemically stabilized orthopedic grade of (known) tetragonal phase zirconia as well as ICDD PDF cards [20] representing powder patterns of three polymorphs of $\mathrm{ZrO}_{2}$ : monoclinic (PDF\# 37-1484), tetragonal (PDF\# 811544), and cubic (PDF\# 49-1642). The peak positions for the spectra of the samples match the corresponding ones for cubic and tetragonal phases within the resolution of the data. We attempted to distinguish the phase identity of the sample by fitting the spectra to extract the experimental lattice parameter(s) (figure 2(c)). The obtained experimental lattice parameter of $5.12 \AA$ is in good agreement with the theoretical value of the bulk cubic phase $(5.10 \AA)$, while the corresponding fitted volumes of tetragonal and monoclinic phases are larger by about $4 \%$ and $10 \%$, respectively. This result significantly contrasts the coexistence of different $\mathrm{ZrO}_{2}$ phases indicated in the XRD spectrum of films prepared by solely e-beam evaporation in our control study (data not shown).

Recently, Lamas et al [20] pointed out that the tetragonal phase identity of $\mathrm{ZrO}_{2}$ nanocrystallites can be verified by observing the splitting of the (400) line of the fluorite-like $\mathrm{ZrO}_{2}$ structure into (004) and (400) lines of the tetragonal phase with more than one degree of separation in their XRD studies. Moreover, the intensity of the (112) Bragg peak should disappear for the cubic phase, but not for the tetragonal phase $\mathrm{ZrO}_{2}$. While no (112) Bragg peak (expected at around $43^{\circ}$ ) is found
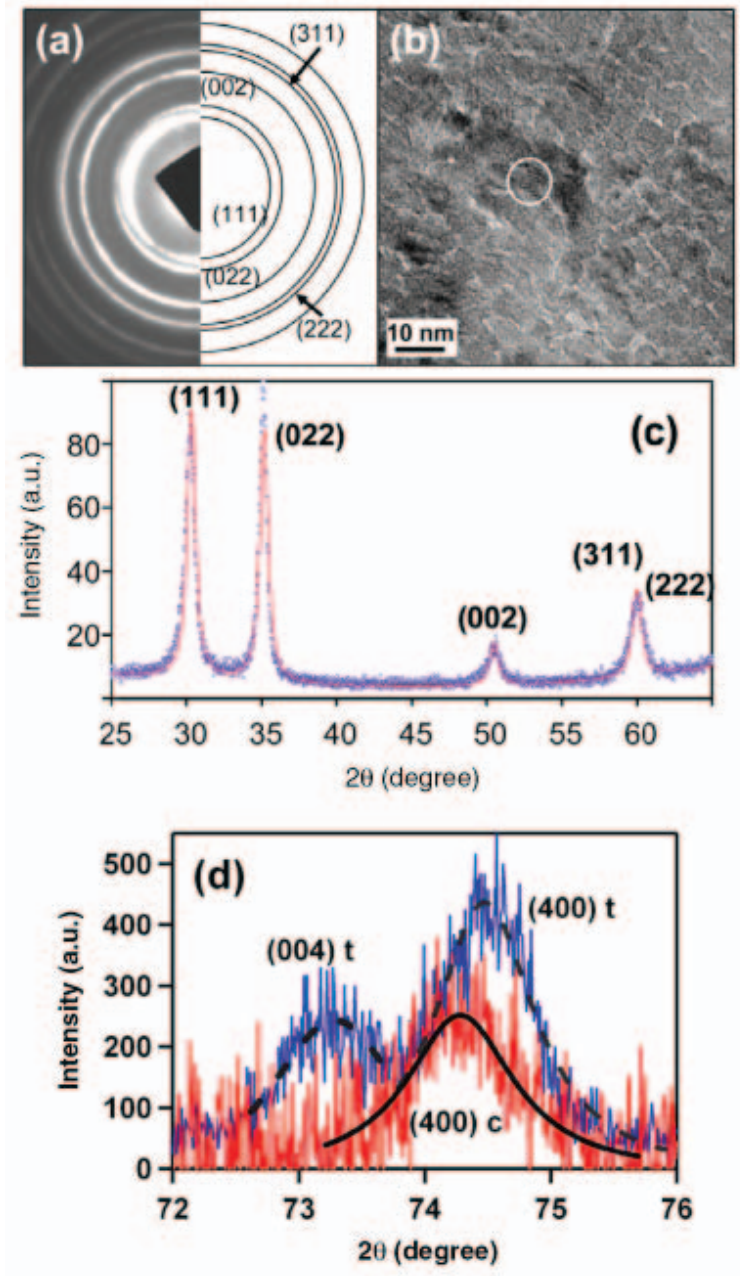

Figure 2. (a) Selected-area diffraction and (b) bright-field TEM image demonstrating the formation of nanocrystalline $\mathrm{ZrO}_{2}$ with 4-15 nm diameter. Circle: crystallite with lattice fringes. (c) X-ray diffraction data show the presence of cubic phase $\mathrm{ZrO}_{2}$ in the films. In particular, the $\mathrm{x}$-ray spectrum demonstrates an excellent fit for cubic phase with a lattice constant of $5.12 \AA$ $\left(\chi^{2}=2.20\right)$. (d) Detailed comparison of the (004) and (400) Bragg peaks for a medical-grade tetragonal $\mathrm{ZrO}_{2}$ sample (top) and the room temperature IBAD $\mathrm{ZrO}_{2}$ films (bottom) $(\mathrm{c}=$ cubic phase, $\mathrm{t}=$ tetragonal phase).

in the XRD data of the NSZ samples, to further prove the cubic phase identity of our samples, we examined the (400) line region in greater detail for our NSZ sample and compared it to that of a medical-grade chemically stabilized tetragonal $\mathrm{ZrO}_{2}$ sample. In figure 2(d), the XRD spectrum of the tetragonal $\mathrm{ZrO}_{2}$ clearly shows the splitting of the (400) line into (004) and (400) lines at ca. $73.2^{\circ}$ and $74.5^{\circ}$ with an intensity ratio of about 1:2. However, the XRD spectrum of the NSZ sample shows only one (400) Bragg peak at ca. $74.3^{\circ}$. Moreover, the almost-symmetric shape of this Bragg peak suggests that it is unlikely to be a merged peak from the (004) and (400) lines of the tetragonal phase due to the line broadening effect caused by the small crystallite size of the NSZ sample. Hence, both the absence of the (112) Bragg peak and the appearance of a single (400) Bragg peak in the XRD data additionally support the formation of the cubic phase in the NSZ sample.

Figure 3 shows the $2.275 \mathrm{MeV} \mathrm{He}{ }^{2+} \mathrm{RBS}$ spectra of an asdeposited $\mathrm{ZrO}_{2}$ film by the IBAD process using ion beam and 


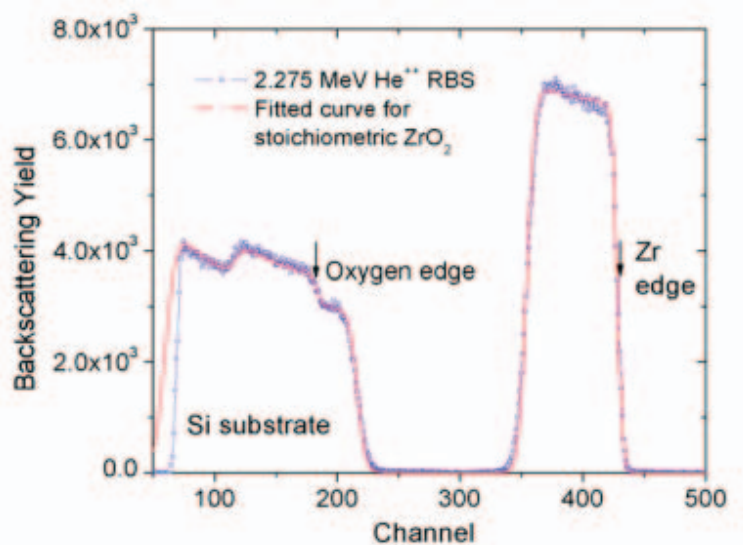

Figure 3. RBS spectra for an as-deposited $\mathrm{ZrO}_{2}$ film on a silicon wafer by an IBAD process at $<150{ }^{\circ} \mathrm{C}$ (circle line) and theoretical fitting model (dotted line).

backfill oxygen gas and the fitted theoretical model. During the RBS, samples were kept perpendicular to the incident ion beam and helium backscattering was observed at $160^{\circ}$. Based on the code used by Charles Evans Associates, the composition of the deposited layer was found to be the same as stoichiometric $\mathrm{ZrO}_{2}$. Formation of stoichiometric $\mathrm{ZrO}_{2}$ is not surprising because of our usage of oxygen energetic ions and backfill oxygen gas during deposition as well as the high heat of formation of $\mathrm{ZrO}_{2}$ [31]. During the deposition of $\mathrm{ZrO}_{2}$, oxygen and argon gas with ratios of $2 / 1$ to $4 / 1$ were used to facilitate plasma formation in the RF or DC plasma ion guns and to increase the current density which was required for our large target area (50 $\mathrm{cm}$ diameter). Since the energy of the ion beam was about only a few hundred electronvolts, there was very little chance for argon atoms to be trapped in the deposited films. No argon signals were even observed in the RBS spectra of as-deposited $\mathrm{ZrO}_{2}$ films on grafoil (carbon) substrates. This is in contrast to the previously reported RBS measurements of $\mathrm{ZrO}_{2}$ films made by IBAD [26] or the ion beam mixing process [25] with $10-150 \mathrm{keV}$ Ar beam where the presence of argon can be easily found in their depth profile data.

Nanoindentation measurements [29, 30] of the NSZ films with thicknesses of $1,000 \mathrm{~nm}$ on silicon substrates for $50 \mathrm{mN}$ load yield a displacement of about $420 \mathrm{~nm}$, a hardness value of $14 \pm 1 \mathrm{GPa}$ and an elastic modulus of $239 \pm 12 \mathrm{GPa}$. However, a load of $5 \mathrm{mN}$ yields a displacement of about $124 \mathrm{~nm}$, a hardness of $16 \pm 1.7$ and an elastic modulus of $223 \pm 15 \mathrm{GPa}$ (see figure 4 for details). A slight variation of nanohardness measurement is related to the effect of film thickness and substrate $[29,30]$. The measured nanohardness of our NSZ films is comparable to the reported microhardness values (9-22 $\mathrm{GPa}$ ) of sputter-deposited calcia-stabilized $\mathrm{ZrO}_{2}$ films on silicon wafers at different deposition temperatures [13].

Using a projector augmented wave first-principle method (included in VASP (Vienna ab initio simulation program) package) [32], we calculated the bulk modulus of cubic phase $\mathrm{ZrO}_{2}$ to be $237 \mathrm{GPa}$ which is considerably larger than the bulk modulus of monoclinic (155 GPa) and tetragonal phases (189 GPa). Thus, the measured bulk modulus of the NSZ films $(223-239 \mathrm{GPa})$ is in extremely good agreement with the calculated bulk value for cubic phase, but not for tetragonal

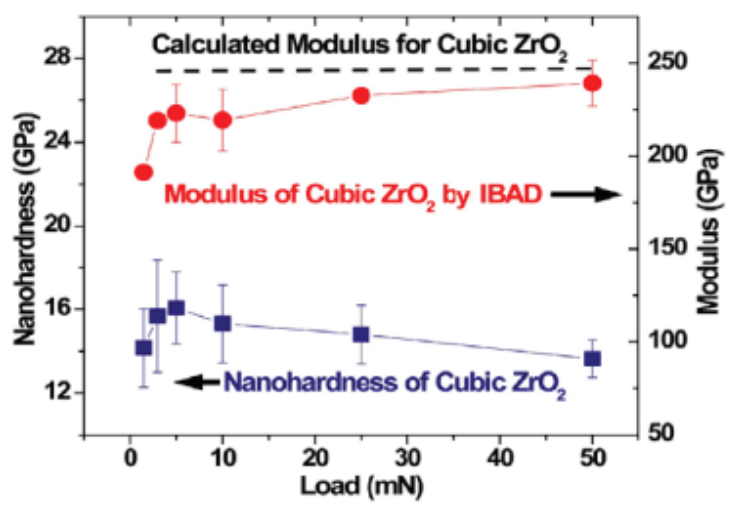

Figure 4. Measurement of nanohardness and modulus of the nanostructurally stabilized $\mathrm{ZrO}_{2}$ films deposited at room temperature and at $500 \mathrm{eV}$ as a function of load.

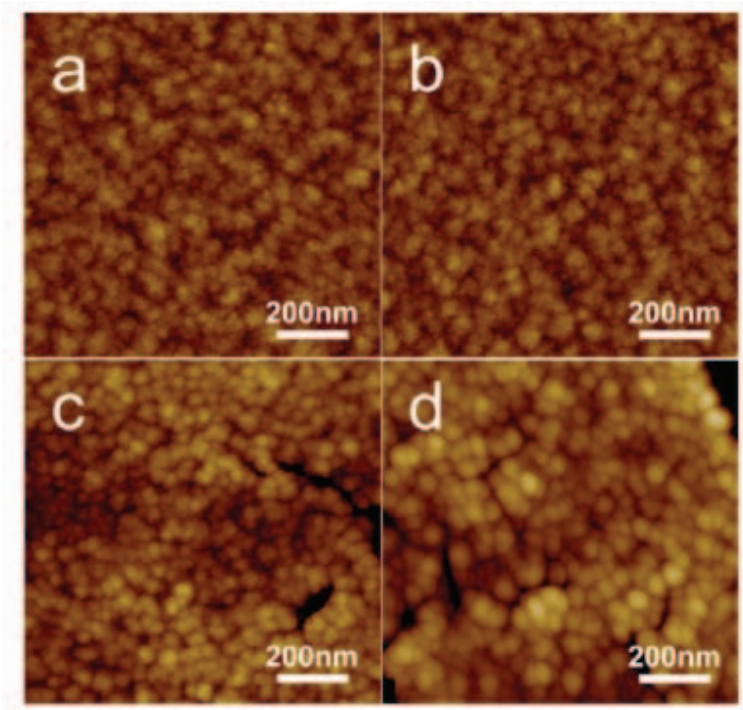

Figure 5. AFM height images of NSZ films (a) without annealing and annealed at (b) $500{ }^{\circ} \mathrm{C}$, (c) $850{ }^{\circ} \mathrm{C}$, and (d) $1000^{\circ} \mathrm{C}$ for $1 \mathrm{~h}$ in air.

phase. This agreement of experimental and calculated values further implies the possible identity of the NSZ films to be of cubic phase.

Thermal annealing of the NSZ samples leads to an increase in the coalescence of grains and transformation of the film atomic structures. Topographical force microscopy images of the annealed films illustrate that the average particle sizes of these films are $12.2 \mathrm{~nm}, 12.5 \mathrm{~nm}, 43.9 \mathrm{~nm}$, and $60.5 \mathrm{~nm}$, corresponding to the annealing temperatures at room temperature, $500{ }^{\circ} \mathrm{C}, 850{ }^{\circ} \mathrm{C}$, and $1000{ }^{\circ} \mathrm{C}$, respectively (figure 5 and table 1). These data indicate significant migration of atoms and thus changes in film atomic structures at high temperatures. The cracking of these films from the silicon substrates begun at temperatures $\geq 850^{\circ} \mathrm{C}$ further suggests the onset of significant phase transformation at $850^{\circ} \mathrm{C}$.

XRD spectra of these annealed NSZ films confirm that these films retain most of their cubic phase XRD signatures up to $850{ }^{\circ} \mathrm{C}$, which is at least $150{ }^{\circ} \mathrm{C}$ higher than the reported phase stability temperature for pure tetragonal materials made by sol-gel methods [21-23] (figure 6). The observed film thermal stability could be attributed to densification of these NSZ 


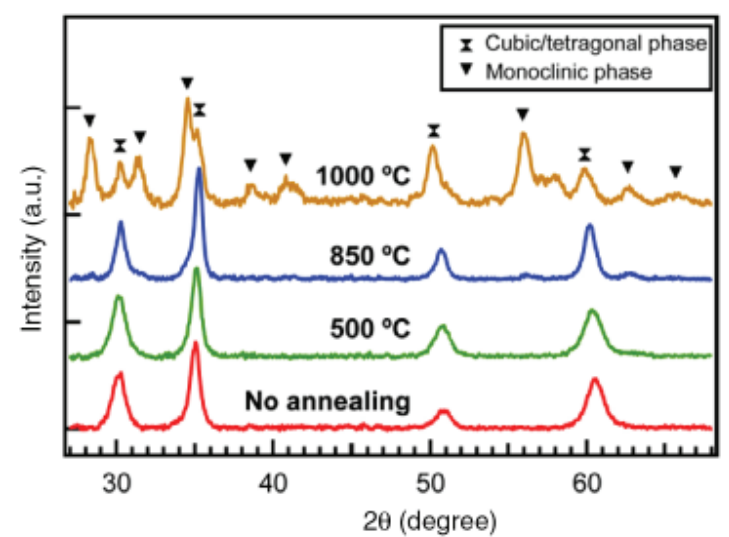

Figure 6. X-ray diffraction spectra of NSZ films without annealing and annealed at 500,850 and $1000^{\circ} \mathrm{C}$ for $1 \mathrm{~h}$ in air.

Table 1. IBAD $\mathrm{ZrO}_{2}$ particle size and roughness evolution determined by AFM as a function of annealing temperature.

\begin{tabular}{lcc}
\hline Annealing temperature $\left({ }^{\circ} \mathrm{C}\right)$ & $R_{\mathrm{a}}(\mathrm{nm})$ & Particle size $(\mathrm{nm})$ \\
\hline Room temperature & 2.8 & $12.3 \pm 2.0$ \\
500 & 2.8 & $12.5 \pm 2.0$ \\
850 & 4.4 & $43.9 \pm 3.5$ \\
1,000 & 6.2 & $60.5 \pm 7.0$ \\
\hline
\end{tabular}

films by the directed ion bombardments at $500 \mathrm{eV}$ during the IBAD process. There is also a coexistence of monoclinic, tetragonal and cubic phases in films annealed at $850-1,000{ }^{\circ} \mathrm{C}$ as revealed by $\mathrm{x}$-ray diffraction. Prolonged annealing of the NSZ films for $10 \mathrm{~h}$ was found to yield similar XRD spectra as the ones with $1 \mathrm{~h}$ annealing. This drastically contrasts the complete monoclinic phase transformation of $\mathrm{ZrO}_{2}$ films made without ion beam bombardment with the same annealing treatment (data not shown).

Our success to create zirconium oxide films of metastable cubic phase without chemical stabilizers can be attributed to a combination of two possible mechanisms and our IBAD sample fabrication technique. First, the control of crystallite size effect has been an important means in nanofabrication for the phase stability of materials. Small crystallites are preferentially produced in the fabrication process so as to introduce high internal pressure inside the crystallites $[18,33]$. According to Young's theory for spherical particles, excess pressure $p$ inside the particle is given by $p=2 \gamma / R$, where $\gamma$ is the surface tension and $R$ is a radius of the particle. A decrease in the size of the crystallites leads to an increase in their internal pressure and hence favors the stability of the phases of materials which would only be stable at high pressure. In our case, both bulk cubic and tetragonal $\mathrm{ZrO}_{2}$ are stable at high pressure. Winterer et al estimated the critical $\mathrm{ZrO}_{2}$ nanocrystallite diameter for the stabilization of the metastable tetragonal phase to be $8-12$ $\mathrm{nm}$, which indicates an effective internal pressure inside the crystallites to be about $2.5 \mathrm{GPa}$ [34]. This size range matches the TEM data of our NSZ films very well. However, in or- der to stabilize the cubic phase, larger internal pressures $(\sim 30$ GPa) are required instead. Thus, the size effect of the crystallite cannot completely justify and explain the possible existence of cubic $\mathrm{ZrO}_{2}$ in our NSZ films and also the similarity of our measured film bulk modulus to that of cubic $\mathrm{ZrO}_{2}$.

The second possible mechanism to stabilize metastable phases of materials is the formation of vacancies in nanostructures [35]. For our present experiments, vacancies in $\mathrm{ZrO}_{2}$ crystallites can be induced by bombardment of directed ion beams in the IBAD process. Furthermore nanocrystalline zirconia with grain sizes less than $10 \mathrm{~nm}$ and with their large surface area and surface to volume ratio stabilized the cubic phase through formation of oxygen vacancies [35], which simulate the effects of chemical trivalent stabilizers such as yttria and ceria. Probably, understanding the origin of this cubic phase is more complicated. Therefore, further investigations are in progress to define all contributing factors that facilitate the formation of the cubic phase in the NSZ samples.

\section{Conclusion}

We have produced transparent hard nanocrystalline $\mathrm{ZrO}_{2}$ films by the IBAD process without the addition of any stabilizing oxide, such as calcia, yttria or ceria. Comparison of XRD data of room temperature deposited $\mathrm{ZrO}_{2}$ with commercially known chemically stabilized tetragonal $\mathrm{ZrO}_{2}$ and nanoindentation studies suggest that these films are of cubic phase. In contrast to $\mathrm{ZrO}_{2}$ films made by sol-gel methods, these NSZ films have better thermal stability, probably because of the absence of porosity due to the nature of the IBAD process. They do not revert to monoclinic phase up to $850{ }^{\circ} \mathrm{C}$. Thus these high adherent transparent films have great potential for wear resistant protective coatings and other biomedical applications $[8,9]$.

\section{Acknowledgments}

The authors are grateful to the support from the Nebraska Research Initiative and University of Nebraska Medical Center, Lincoln and Omaha. We thank Harry Kawayoshi and Brian Jones for helpful discussions about the TEM and XRD data. We also thank Professor Michael Graham (Northwestern University) for the nanoindentation measurements.

\section{References}

[1] Garvie R C, Hannink R H, and Pascoe R T 1975 Ceramic steels? Nature 258703

[2] Wilk G D, Wallace R M, and Anthony J M 2001 High-k gate dielectrics: current status and materials properties considerations J. Appl. Phys. 895243

[3] Zhang Q, Shen J, Wang J, Wu G, and Chen L 2000 Sol-gel derived $\mathrm{ZrO}_{2}-\mathrm{SiO}_{2}$ highly reflective coatings Int. J. Inorg. Mater. 2319

[4] Wright P K and Evans A G 1999 Mechanisms governing the performance of thermal barrier coatings Curr. Opin. Solid State Mater. Sci. 4255 
[5] Zhou X, Balachov I, and Macdonald D D 1998 The effect of dielectric coatings on IGSCC in sensitized type 304 SS in high temperature dilute sodium sulfate solution Corros. Sci. 401349

[6] Nguyen T and Djurado E 2001 Deposition and characterization of nanocrystalline tetragonal zirconia films using electrostatic spray deposition Solid State Ion. 138191

[7] Breen J P and Ross J R H 1999 Methanol reforming for fuelcell applications: development of zirconia-containing $\mathrm{Cu}-\mathrm{Zn}-$ Al catalysts Catal. Today $\mathbf{5 1 5 2 1}$

[8] Namavar F, Jackson J D, Sharp J G, Mann E E, Bayles K, Cheung C L, Feschuk C, Varma S, Haider H, and Garvin K L 2007 Searching for smart durable coatings to promote bone marrow stromal cell growth while preventing biofilm formation BiofilmMaterial Interactions-New Tools, Technologies and Opportunities (Mater. Res. Soc. Symp. Proc. vol. 954E) ed M Libera, T Camesano, B Kreiswirth, P Li, and R G Richards (Warrendale, PA: Materials Research Society) p 0954-H04-04

[9] Jackson J D, Sharp J G, Haider H, Garvin K L, and Namavar F 2006 Preliminary analysis of attachment, survival and growth of bone marrow stromal cells on nanocrystalline hard ceramic coatings Ceramics, Cells and Tissues: Materials for Scaffolding of Biologically Engineered Systems. Interfaces and Interactions on a Nanoscale ed A Ravaglioli and A Krajewski (Rome: Consiglio Nazionale Delle Ricerche) p 109

[10] Garvie R C and Nicholson P S 1972 Phase analysis in zirconia systems J. Am. Ceram. Soc. 55303

[11] Piconi C and Maccauro G 1999 Zirconia as a ceramic biomaterial Biomaterials 201

[12] Lange F F 1982 Transformation toughening: part 3, experimental observations in the $\mathrm{ZrO}_{2}-\mathrm{Y}_{2} \mathrm{O}_{3}$ system J. Mater. Sci. 17240

[13] Pakala M, Walls H, and Lin R Y 1997 Microhardness of sputterdeposited zirconia films on silicon wafers J. Am. Ceram. Soc. 801477

[14] Lajavardi M, Kenney D J, and Lin S H 2000 Time-resolved phase transition of the nanocrystalline cubic to submicron monoclinic phase in zirconia J. Chin. Chem. Soc. 471043

[15] Gateshki M, Petkov V, Williams G, Pradhan S K, and Ren Y 2005 Atomic-scale structure of nanocrystalline $\mathrm{ZrO}_{2}$ prepared by high-energy ball milling Phys. Rev. B 71224107

[16] Bouvier P, Djurado E, Lucazeau G, and Le Bihan T 2001 Highpressure structural evolution of undoped tetragonal nanocrystalline zirconia Phys. Rev. B 628731

[17] Miller R A and Berndt C C 1984 Performance of thermal barrier coatings in high heat flux environment Thin Solid Films 119 195

[18] Shukla S and Seal S 2005 Mechanisms of room temperature metastable tetragonal phase stabilization in zirconia Int. Mater. Rev. $\mathbf{5 0} 45$

[19] Rush G E, Chadwick A V, and Kosackiz I 2000 An EXAFS study of nanocrystalline yttrium stabilized cubic zirconia films and pure zirconia powders J. Phys. Chem. B 1049597

[20] Lamas D G, Rosso A M, Suarez M, Anzorena A, Fernandez A, Bellino M G, Cabezas M D, Walsoe de Reca N E, and Craievich A F 2006 Crystal structure of pure $\mathrm{ZrO}_{2}$ nanopowders $\mathrm{Scr}$. Mater. 55553
[21] Suyama R, Ashida R, and Kume S 1985 Synthesis of the orthorhombic phase of $\mathrm{ZrO}_{2}$ J. Am. Ceram. Soc. $68 \mathrm{C} 314$

[22] Jouanne M, Morhange J F and Kanehise M A 2001 Structural transformation in nanosized zirconium oxide Phys. Rev. B 65 155404

[23] Brioude A, Lequevre F, Mugnier J, Bovier C, Dumas J, and Plenet J C 2002 Densification and nanocrystallisation of sol-gel $\mathrm{ZrO}_{2}$ thin films studied by surface plasmon polariton-assisted Raman spectroscopy Eur. Phys. J. B 26115

[24] Martin P 1990 Ionization-assisted evaporative processes: techniques and film properties IEEE Trans. Plasma Sci. 18855

[25] Neubeck K, Lefaucheut C-E, Hahn H, Balogh A G, Baumann H, Bethge K, and Ruck D M 1995 Ion beam mixing and radiation enhanced diffusion in metal/ceramic interfaces Nucl. Instrum. Methods Phys. Res. B 106589

[26] Neubeck K, Nitsche R, Hahn H, Alberts L, Wolf G K, and Friz M 1995 Ion beam assisted deposition of $\mathrm{ZrO}_{2}$ thin films $\mathrm{Nucl}$. Instrum. Methods Phys. Res. B 106110

[27] Namavar F, Budnick J I, Fasihuddin A, Sanchez F H, and Hayden H C 1986 Study of dose and dose rate in the implantation of nitrogen isotopes into silicon (100) Semiconductoron-Insulator and Thin Film Transistor Technology Symposium (Mater. Res. Soc. Symp. Proc. vol. 53) ed A Chiang, M W Geis, and L Pfeiffer (Pittsburgh, PA: Materials Research Society), p 281.

[28] Tan Z, Budnick J L, Pease D M and Namavar F 1991 X ray absorption studies of krypton precipitates in solid matrices Phys. Rev. B 431987

[29] Oliver W C and Pharr G M 1992 An improved technique for determining hardness and elastic modulus using load and displacement sensing indentation experiments J. Mater. Res. 71564

[30] Doerner M F and Nix W D 1986 A method for interpreting the data from depth sensing indentation instruments $J$. Mater. Res. 1601

[31] Karapetyants M K and Karapetyants M L 1970 Thermodynamic Constants of Inorganic and Organic Compounds (London: Ann Arbor Humphrey Science Publishers)

[32] Kresse G and Furthmuller J 1996 Efficient iterative schemes for $a b$ initio total-energy calculations using a plane-wave basis set Phys. Rev. B 5411169

[33] Jurado E, Bouvier P, and Lucazeau G 2000 Crystallite size effect on the tetragonal-monoclinic transition of undoped nanocrystalline zirconia studied by XRD and Raman spectrometry $J$. Solid State Chem. 149399

[34] Winterer M, Nitsche R, Redfern S A T, Schmahl W W, and Hahn H 1995 Phase stability in nanostructured and coarse grained zirconia at high pressures Nanostruct. Mater. 5679

[35] Fabris S, Paxton A T, and Finnis M W 2002 A stabilization mechanism of zirconia based on oxygen vacancies only Acta Mater. 505171 